\title{
Christianity and Subjective Wellbeing: A Study of Hong Kong
}

\author{
Lufanna Ching-han Lai \\ Department of Counselling and Psychology, The Hong Kong Shue Yan University, Hong Kong, China
}

\section{Email address:}

lufanna@yahoo.com.hk

\section{To cite this article:}

Lufanna Ching-han Lai. Christianity and Subjective Wellbeing: A Study of Hong Kong. Psychology and Behavioral Sciences. Vol. 10, No. 1, 2021, pp. 56-62. doi: 10.11648/j.pbs.20211001.17

Received: February 2, 2021; Accepted: February 15, 2021; Published: February 23, 2021

\begin{abstract}
This paper examined the relationship between Christianity and subjective wellbeing by embedding in a revised homeostatic model of subjective wellbeing (SWB) which integrates the affective (homeostatically protected mood: content, happy and excited), cognitive (self-esteem, optimism and perceived control: primary control and secondary control) and experiential factors relating to SWB. In Christianity, God is the creator and lord of life and its doctrine advocates self-abnegation and committing to God; hence, three hypotheses were tested as: First, compared with those without religious belief, the Christians would be higher in SWB, secondary control and optimism, but lower in primary control and self-esteem. Second, for the Christians, each of the cognitive factors of secondary control and optimism would predict more significant SWB variance beyond the other homeostatic model factors than that of primary control and self-esteem. Third, compared with those without religious belief, each of the cognitive factors of secondary control and optimism for Christians would predict more significant SWB variance beyond the other homeostatic model factors, while that of primary control and self-esteem would predict less significant SWB variance. Four hundred and eighteen Chinese respondents were recruited in Hong Kong (178 Christians and 240 without religious belief) to complete a questionnaire. The results revealed that no significant intergroup difference was found on SWB and all cognitive factors. Besides, while Christians' optimism predicted more significant SWB variance than primary control (3\%) and self-esteem (1\%), their secondary control failed to make any independent contribution. Additionally, compared with those without religious belief, Christians' primary control (2\%) and self-esteem (3\%) explained lesser significant SWB variance. However, while Christians' optimism predicted more significant variance (3\%) than those without religious belief, secondary control for each of the groups failed to make any independent contribution. The results were discussed in terms of inappropriateness and non-specificity of the scale used in measuring secondary control, and a newly proposed construct of religious self-esteem.
\end{abstract}

Keywords: Christianity, Subjective Wellbeing, Self-esteem, Optimism, Primary Control, Secondary Control

\section{Introduction}

Christianity is a monotheistic religion. In the Bible, the holy scripture of Christianity, the Christianity-God is depicted as the creator and sustainer of all creatures and things (Genesis 1), and is believed as omnipotent, omnipresent and omniscient (1Samuel 2:3; Psalms 65:6). Hence, in order to lead a happy life, the followers should build up a personal relationship with God [19] characterized by faith, trust, submission and obedience [33, 35]. This study examined the relationship between Christianity and subjective wellbeing (SWB) with the use of the theoretical framework of a revised homeostatic model of SWB, which integrates the affective (content, happy and excited), cognitive (self-esteem, optimism and perceived control) and experiential factors in relation to SWB [20]. This allows for a systematic understanding of the factors pertaining to SWB of Christians in particular the cognitive ones, viz. self-esteem, optimism and perceived control.

\section{Literature Review}

\subsection{Normative Levels of Subjective Well-Being}

SWB is the affective and cognitive evaluation people make 
about how happy and satisfied they are with their lives $[2,12$, 15]. In the field of psychology, many studies support the view that SWB is relatively stable and moderately positive $[5,9,13]$ For instance, Cummins [7] combined the population means from 16 life satisfaction studies conducted in Western nations. Data were standardized to a statistic called the percentage of scale maximum $(\% \mathrm{SM})$ which converts scale scores into percentages. Aggregates of mean values yielded a mean of 75 and a standard deviation (SD) of 2.5. Hence, the range $70-80 \% \mathrm{SM}$ described two SDs around the mean and was defined as the normative range of SWB. However, inclusion of non-Western nations revealed that the mean of SWB was 70
$(\mathrm{SD}=5)$, thus causing the normative range to expand downward, to $60-80 \%$ SM [8]. Lai, Cummins and Lau [21] explained that this downward expansion may be due to the poverty and disadvantage in economically underdeveloped countries and/or the influence of cultural response bias acting specifically within Confucian-based cultures.

\subsection{Subjective Wellbeing Homeostasis}

In a bid to explain the stable positivity of SWB described above, a revised homeostatic model of SWB is adopted:

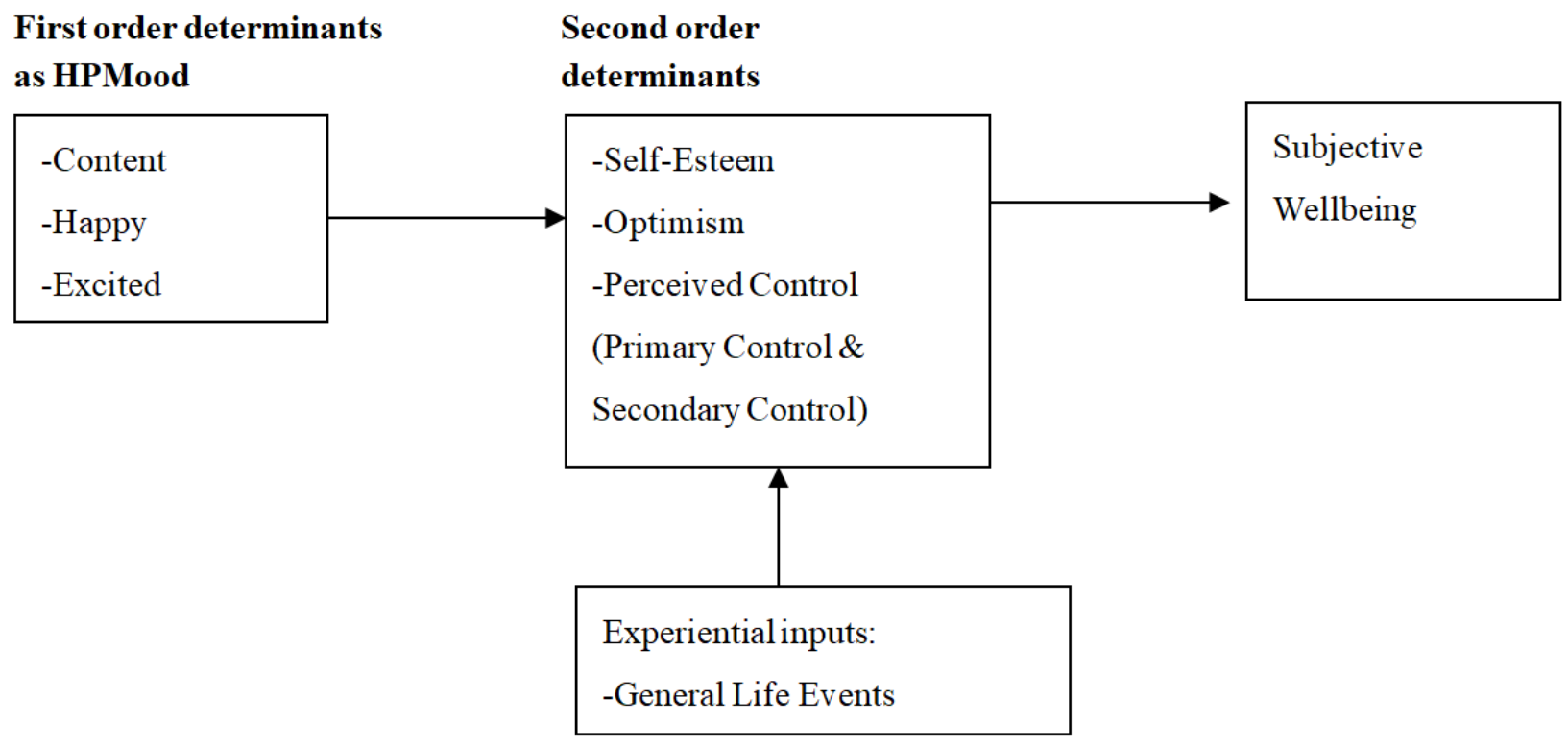

\section{Third order determinants as experiential input}

Figure 1. A Revised Homeostatic Model of Subjective Wellbeing [20].

The affective factor of homeostatically protected mood (HPMood) is a construct evolved from core affect [30], in that core affect is the neurophysiological state consciously accessible as the simplest raw (non-reflective) feelings. In a similar vein, HPMood exists without reference to objects or events [10]. It is proposed as a genetically determined, constant positive affective background pervading many thought processes but most especially those that are evaluative of personal and general characteristics. The archetypical form of such evaluative is 'How satisfied are you with your life as a whole?' It is found that the response to this item to be heavily saturated with HPMood [14]. Based on the above conceptualization and use of structural equation modelling, HPMood is discovered to be comprised of three affects - content, happy and excited [14]. Besides, HPMood is found to be the basis of SWB set-point and positive mood defended by homeostasis [14]. Moreover, each of the cognitive buffers - self-esteem, optimism and perceived control is found to assist in the process of defending HPMood against life experiences [11].
Referring to Figure 1, the way Christianity is related to SWB will be discussed in terms of primary control, secondary control, optimism and self-esteem.

\subsubsection{Perceived Control}

According to Weisz et al. [38], perceived control is defined as an individual's perceived ability to change a situation and overcome challenges to achieve a desired outcome. This can be gained through primary control by influencing existing physical, social or behavioral realities to fit their perceptions, goals or wishes [38], or by secondary control which brings themselves into line with the realities [38]. It is likely that Christianity teaching mainly increases the use of secondary control and thereby promotes SWB as follows:

When Christians encounter life adversities that are out of their control or beyond their means to tackle, they can appeal to God; as He is the living God (Daniel 6:20), as well as a reliable, abundant and generous source of help readily available to humans (Psalms 84:11) [33]. The followers can obtain vicarious control by subordinating themselves to God [38]. All they need to do in garnering such assistance is simply 
to exercise their faith and trust in God's power and promise; and to be obedient and submissive to His plan and arrangements [33]. In this way, they can psychologically regain control of any adverse situations, as well as gaining the strength and confidence for living resulted from associating vicariously with the all-powerful God.

Additionally, the Christians can attain control by searching for the meaning of events. It is postulated that human beings have the internal or dispositional tendency to make sense of all phenomena; otherwise, they feel unsatisfied and uncomfortable [34]. In this light, interpretive control is a cognitive attempt to modify people's views of the otherwise uncontrollable situations and thereby effect a better fit with the realities [29, 38]. Hence, Christianity provides the interpretative framework for understanding some fundamental questions of life for which people need answers. For example, men are created by God with a plan intended for each of them, and all human sufferings are planned by God serving the purpose of spiritual education to equip people for ministry.

Compared to secondary control, primary control, which involves a person actively changing the environment to fit his needs and desires [29], is less relevant as a life coping skill for Christians. According to the Christian faith, God is the lord of life and $\mathrm{He}$ understands humans more than they understand themselves [33]. Hence, Christians may believe that they should always be obedient and accepting of whatever God plans and arranges for them (John 15:9-11) and that any self-initiated action to change life's circumstances will ruin God's good and intended plan [33]. Accordingly, it is inferred that the adoption of secondary control, rather than primary control, is a more relevant and appropriate coping strategy for Christians.

In short, by aligning with God and cognitively re-evaluating life situations, the Christians are allowed some degree of secondary control, in the form of better accepting the situations and enhancing their satisfaction with them [29]. Hence, secondary control, rather than primary control, seem more relevant in enhancing their SWB.

\subsubsection{Optimism}

Optimism refers to the perception that the future will be to the perceivers' advantage or for their pleasure [26]. As abovementioned, subordinating to God will help Christians increase their strength and confidence in tackling adversities, from which to release negative emotions such as fear, anxiety and worry, as well as to promote the feeling of hope. Based on their belief in God, they are able to transcend their present predicament and envision the blissful future [23]. Hence, the Christianity-God can be understood as the coping resources for promoting the level of optimism, thereby enhancing the believers' resilience to the stresses of life and leading to higher SWB.

\subsubsection{Self-Esteem}

It refers to the degree to which an individual experiences oneself as worthy and capable [28]. As Christianity teaches that God is the creator and lord of life, and that the values of life should be derived from God; it is likely that SWB of Christians is not dependent on self-esteem, which is elaborated as follows:

Becoming the followers of God implies the humble state of being the servant of God (Luke 1:48), and at the core of servanthood is the requirement of self-denial. Just like the Bible says "If anyone would come after Me, he must deny himself and take up his cross daily and follow Me" (Luke 9:23). To this effect, Christianity's belief system is characterized as self-abnegation $[25,36]$. For example, being followers of God are required to put up the values of loving others as oneself and even to sacrifice oneself for helping and serving others. All these values blatantly run counter to self-oriented mentality.

Moreover, the Bible tells that owing to the sin of humans' ancestor (Adam and Eve), all men become the captive of sin; thus culminating in death (Romans 6:23). However, thanks to God's loving kindness, He prepared for the salvation of men by sending His son Jesus into the world and dying on the cross, which is the remedy for the defilement of $\sin$ (Romans 5:8; 1John 4:10). In effect, Christianity supposes that all men are sinners from which they had been mercifully redeemed by Jesus; and this concept of sin tends to lower the feeling of self-esteem of the believers [32].

Furthermore, individuals tend to have pride in themselves. Pride is produced by the sense of self-worth and enables individuals to obtain pleasure or gratification from thinking highly of themselves [22]. However, in Christianity, pride is condemned as a vice or sin incompatible with the religious faith [22]. For instance, the Christianity-God has given every person some special abilities mainly for the aim of helping and benefiting one another, rather than for selfish purposes or boasting of oneself (1Peter 4:10). Hence, if people do not accept these conditions of human existence and their dependence on God, but think that what they possess is completely a product of their own ability, it is virtually a kind of $\sin$ i.e., a prideful rebellion against $\operatorname{God}[1,31]$. Correspondingly, the esteem and satisfaction one might feel in a given accomplishment is misguided unless it is referred back to God [16].

In sum, the esteem of Christians is grounded not in what they do or who they are, but in God. Also, it is related to whether they have fulfilled what God wants them to do. Taken together, it is postulated that the self-esteem of Christians has no direct bearing on their SWB.

Overall, the SWB of Christians seems to be intimately and positively related to secondary control and optimism but not closely related to primary control and self-esteem. Hence, it is predicted that, compared with those without religious belief, the Christians will score higher in SWB, secondary control and optimism but lower in primary control and self-esteem. Besides, it is expected that for the Christians, secondary control and optimism will predict more significant SWB variance beyond the other homeostatic model factors than primary control and self-esteem. Additionally, compared with those without religious belief, it is expected that secondary control and optimism of Christians will explain more unique 
SWB variance beyond the other homeostatic model factors, while primary control and self-esteem will predict less unique variance.

\section{Methods}

\subsection{Participants}

Through convenience sampling, 178 Christians and 240 participants without religious belief were drawn. These 418 Chinese samples participated in a survey by completing a questionnaire.

The demographic characteristics of these two groups are comparable, in that both were slightly dominated by females, middle-aged adults (36-45 years) and high-income group (HKD20,001 \& above).

\subsection{Measures}

SWB. It was measured by the Personal Wellbeing Index (PWI) [17]. The scale is comprised of 8 questions regarding satisfaction with 8 life domains as: standard of living, health, achievement, relationships, safety, community-connectedness, future security and spirituality-religion. The mean of the domain scores derived from PWI constitutes a measure of SWB. The reliability coefficient for the current study was .88 .

HPMood. The 3 affective predictors of content, happy and excited were measured by asking participants to indicate how each of them described their feelings when they thought about their life in general. The coefficient alpha of .85 was obtained in this study.
Experiential Input. General life events were measured by asking participants whether anything had happened recently that caused them to feel happier or sadder than normal. Participants were asked to respond to three categories of response: 'yes, happier' $=3$, 'no' $=2$ and 'yes, sadder' $=1$.

Perceived Control. It was measured by a six-item scale comprising 2 subscales, i.e., primary and secondary control, each of which consists of 3 items. This scale was extracted from [4] which originally consists of nine items including the measure of relinquished control. The coefficient alpha of .83 was obtained in this study.

Optimism. It was measured using the Life Orientation Test - Revised (LOT-R) [3]. This six-item scale was comprised of items framed either in an optimistic or pessimistic fashion. This survey only used the three optimistically framed questions. In this study, the reliability coefficients reported for this three-item scale was .79.

Self-Esteem. It was measured by the ten-item Rosenberg Self-Esteem Scale [28]. The coefficient alpha reported in this study was .78.

\section{Results}

\subsection{Hypothesis 1}

Compared with those without religious belief, the Christians would be higher in SWB, secondary control and optimism, but lower in primary control and self-esteem.

This hypothesis was tested by performing t-tests with the results provided as follows:

Table 1. Comparison of Christians and those without religious belief on the measured variables.

\begin{tabular}{lllllllllll}
\hline \multirow{2}{*}{ Groups } & SWB & \multicolumn{4}{c}{ Primary Control } & \multicolumn{2}{c}{ Secondary Control } & Optimism & \multicolumn{2}{c}{ Self-Esteem } \\
\cline { 2 - 11 } & Mean & SD & Mean & SD & Mean & SD & Mean & SD & Mean & SD \\
\hline Christians & 66.83 & 12.99 & 73.69 & 14.53 & 71.86 & 19.36 & 69.77 & 16.25 & 62.79 & 11.42 \\
Without Religious Belief & 65.61 & 12.51 & 74.29 & 13.21 & 71.45 & 16.38 & 66.92 & 16.80 & 61.93 & 12.40 \\
$\mathrm{t}$-test each column & $\mathrm{t}(378)=-0.93, \mathrm{p}=.356$ & $\mathrm{t}(412)=0.44, \mathrm{p}=.662$ & $\mathrm{t}(413)=-0.23, \mathrm{p}=.818$ & $\mathrm{t}(401)=-1.71, \mathrm{p}=.088$ & $\mathrm{t}(400)=-0.71, \mathrm{p}=.471$ \\
\hline
\end{tabular}

Note. SWB for the Christians was the average of 8 life domains while that for those without religious belief was the average of 7 domains excluding spirituality-religion.

No significant intergroup difference was found for all variables.

\subsection{Hypothesis 2}

For the Christians, each of the cognitive factors of secondary control and optimism would predict more significant SWB variance beyond the other homeostatic model factors than that of primary control and self-esteem.

\subsection{Hypothesis 3}

Compared with those without religious belief, each of the cognitive factors of secondary control and optimism for Christians would predict more significant SWB variance beyond the other homeostatic model factors, while that of primary control and self-esteem would predict less significant SWB variance.

Both hypotheses would be tested by doing hierarchical multiple regression. In testing each of the hypotheses, hierarchical multiple regression was performed with life events and HPMood entered in Model 1, and primary control, secondary control, optimism and self-esteem in Model 2. Prior to running the main analyses, several multiple regression assumptions were tested. Taking into account the number of independent variables, the sample size was adequate. The values for variance inflation and tolerance were below 10 and above 0.10; hence, there was no problem with multicollinearity [24]. Moreover, the results of the residuals scatterplot and the normal probability plot indicated that the assumptions of normality, linearity and homoscedasticity of residuals were not violated. A summary of results is provided below: 
Table 2. A Summary of Hierarchical Regression Analyses for Christians and Those without Religious Belief.

\begin{tabular}{|c|c|c|c|c|c|c|c|c|}
\hline & \multicolumn{4}{|c|}{ Christians } & \multicolumn{4}{|c|}{ Without Religious Belief } \\
\hline & $\boldsymbol{\beta}$ & $s r^{2}(\%)$ & $R^{2}$ & $\Delta R^{2}$ & $\boldsymbol{\beta}$ & $s r^{2}(\%)$ & $R^{2}$ & $\Delta R^{2}$ \\
\hline \multicolumn{9}{|l|}{ Model 1} \\
\hline -Life Events & -0.07 & - & $0.52^{* * *}$ & & 0.03 & - & $0.39^{* * *}$ & \\
\hline -HPMood & $0.71^{* * *}$ & $0.50(50)$ & & & $0.63^{* * *}$ & $0.39(39)$ & & \\
\hline \multicolumn{9}{|l|}{ Model 2} \\
\hline -Life Events & 0.02 & - & $0.61^{* * *}$ & $0.09^{* * *}$ & 0.10 & - & $0.52^{* * *}$ & $0.13^{* * *}$ \\
\hline -HPMood & $0.41^{* * *}$ & $0.08(8)$ & & & $0.33^{* * *}$ & $0.05(5)$ & & \\
\hline -Primary Control & -0.01 & - & & & $0.18^{* *}$ & $0.02(2)$ & & \\
\hline -Secondary Control & 0.03 & - & & & 0.04 & - & & \\
\hline -Optimism & $0.27^{* *}$ & $0.03(3)$ & & & 0.12 & - & & \\
\hline $\begin{array}{l}\text {-Self-Esteem } \\
\text { (SWB: DV) }\end{array}$ & $0.22^{* * *}$ & $0.02(2)$ & & & $0.26^{* * *}$ & $0.05(5)$ & & \\
\hline
\end{tabular}

$* * * p<.001 . * * p<.01 . * p<.05$.

Note. SWB for the Christians was the average of 8 life domains while that for those without religious belief was the average of 7 domains excluding spirituality-religion.

In Model 2, both primary and secondary control of the Christian group failed to predict any significant SWB variance. Despite this, optimism of Christian group predicted more significant SWB variance than primary control and self-esteem respectively by $3 \%$ and $1 \%$. Hence, Hypothesis 2 is partially supported.

For those without religious belief, both secondary control and optimism failed to make any independent contribution to SWB in Model 2. Comparison of two groups' results revealed that Christians' primary control and self-esteem accounted for lesser significant SWB variance respectively by $2 \%$ and $3 \%$, and that their optimism made more independent contribution to SWB by $3 \%$. Thus, Hypothesis 3 is partially supported.

\section{Discussion}

Although no significant difference was found between Christians and those without religious belief on all studied variables, the cognitive factor of optimism did contribute $3 \%$ unique variance in explaining Christians' SWB while none was found for those without religious belief. Also, Christians' optimism accounted for higher SWB variance than primary control and self-esteem respectively by $3 \%$ and $1 \%$. Moreover, compared with those without religious belief, primary control and self-esteem of Christians explained respectively $2 \%$ and $3 \%$ lesser SWB variance. These results lend support to the predictions that Christianity belief, on one hand helps promote optimism, but on the other hand dissuades the use of primary control and hampers self-esteem.

The failure of primary control in explaining any SWB variance seems to be supportive of the view that Christians are less likely to use it as a life coping strategy. According to the Bible, God is love and always acts in people's best interest, to the extent of letting them go through temptations and trials from which to benefit their growth (Hebrews 5:8-9). In this light, people should always try to be obedient to whatever God plan and arrange for them, as well as to submit their troubles and problems of life to Him by simply taking their hands off the task and leaving God to work (Psalms 37:5). However, the findings that Christians' secondary control also failed to contribute any SWB variance is surprising, given the widespread belief that vicarious association with the powerful others (deities) enables the religious adherents to experience an enhanced sense of strength and power [18, 29, 38]. Additionally, it was found that the level of secondary control for the adherents of Christianity is not significantly higher than those without religious belief. One possible explanation may be that the secondary control scale used in this study, which comprises only 3 items (when something bad happens to me, I remind myself something good may come of it; I remind myself I am better off than others; and I remind myself situation will improve if I am patient), are not relevant or specific enough to probe the vicarious and/or interpretive techniques that are mainly taught to the Christians. It may therefore be useful for a more specifically designed control scale to be developed, in an effort to measure secondary control exercised by Christians.

As predicted, while optimism made 3\% independent contribution to the SWB of Christians, none was made for those without religious belief. Besides, among the cognitive factors, optimism explained higher significant SWB variance than that of primary control and self-esteem; and is indeed the major source of contributor to the SWB of Christians. These findings lend credence to the extant literature that people with religious belief are more optimistic than those without religious belief $[6,27,37]$. In short, it seems that the Christianity belief allows the followers to have a renewed sense of hope in facing life difficulties, as well as to look forward to the unknown future with full hope (Psalms 23:4; Matthew 28:20).

Compatible with the predictions made in Hypothesis 2 and 3, Christians' self-esteem (3\%) explained lesser SWB variance than optimism (2\%) and made lesser independent contribution to SWB compared with those without religious belief $(5 \%)$. These findings are supportive of the presumption that SWB of Christians is less dependent on self-esteem. In line with this, there may perhaps be another source of esteem specifically for Christians which is complementary to self-esteem. This source of influence is proposed as religious self-esteem, referring to the sense of worthiness people derived from evaluating themselves against the values, virtues and morality of Christianity belief. This religious self-esteem 
is also proposed to be related to SWB in much the same way as self-esteem.

\section{Conclusion}

The study of Christians' SWB in a homeostatic model rendered a more comprehensive understanding in regard to the role and importance of the three cognitive factors concerned. To validate these findings, a further study aims at establishing the causation among the studied variables is warranted. Besides, given the limitation of this study is the use of convenience sampling and the relatively small sample size, a larger sample by means of systematic sampling method is required. Moreover, the inappropriateness and non-specificity of the existing scale in measuring Christians' secondary control necessitates the development of a new one in understanding the control techniques used by Christians. Additionally, the conduct of further study on the proposed construct of religious self-esteem may render a better understanding of the Christians' esteem and its relationship with SWB.

\section{References}

[1] Baasten, M. (1986). Pride according to Gregory the Great. Queenstown: Edwin Mellon Press.

[2] Campbell, A., Converse, P. E., \& Rodgers, W. L. (1976). The quality of American life: Perceptions, evaluations, and satisfactions. New York: Russell Sage Foundation.

[3] Carver, C. S., \& Scheier, M. (2003). Optimism. In S. J. Lopez, \& C. R. Sydner (Eds.), Positive psychological assessment: handbook of models and measures. Washington, DC: American Psychological Association.

[4] Chambers, S., Hollway, J., Parsons, E-R., \& Wallage, C. (November, 2003). Perceived control and wellbeing. Paper presented at the $5^{\text {th }}$ Australian Conference on Quality of Life, Melbourne, Australia.

[5] Cook, V. (2002). A new direction for Quality of Life: Evaluating the Comprehensive Quality of Life Scale as a measure of satisfaction and depression. Melbourne: Australian Centre on Quality of Life, School of Psychology, Deakin University.

[6] Cotton, S., Puchalski, C. M., Sherman, S. N., Mrus, J. M., Peterman, A. M., \& Feinberg, J., et al. (2006). Spirituality/Religion in patients with HIV. Journal of General Internal Medicine, 21, S5-S13.

[7] Cummins, R. A. (1995). On the trail of the gold standard for subjective well-being. Social Research Indicators, 35, 179-200.

[8] Cummins, R. A. (1998). The second approximation to an international standard for life satisfaction. Social Indicators Research, 43, 307-334.

[9] Cummins, R. A. (2003). Normative life satisfaction: Measurement issues and a homeostatic model. Social Indicators Research, 64, 225-256.
[10] Cummins, R. A. (2010). Subjective wellbeing, homeostatically protected mood and depression: A synthesis. Journal of Happiness Studies, 11, 1-17.

[11] Cummins, R. A., \& Nistico, H. (2002). Maintaining life satisfaction: The role of positive cognitive bias. Journal of Happiness Studies, 3, 37-69.

[12] Cummins, R. A., Gullone, E., \& Lau, A. L. D. (2002). A model of subjective well-being homeostasis: The role of personality. The Universality of Subjective Well-Being Indicators, 7-46.

[13] Cummins, R. A., Lau, A. L. D., Mellor, D., \& Stokes, M. A. (2009). Encouraging governments to enhance the happiness of their nation: Step 1: Understand subjective well-being. Social Indicators Research, 91, 23-36.

[14] Davern, M., Cummins, R. A., \& Stokes, M. (2007). Subjective well-being as an affective/cognitive construct. Journal of Happiness Studies, 8, 429-449.

[15] Diener, E. (2000). Subjective well-being: The science of happiness and a proposal for a national index. American Psychologist, 55, 34-43.

[16] Important-For the right reasons. (1996). Christian Science Monitor, 88(168), 14-25.

[17] International Wellbeing Group. (2006). Personal Wellbeing Index-Adult (PWI-A).

[18] Johnson, R. D., \& Downing. L. L. (1979). Deindividuation and valence of cues: Effects on prosocial and antisocial behavior. Journal of Personality and Social Psychology, 37, 1523-1538.

[19] King, D. L. (2015). The lived experience with Christianity and teenage African-American females' perceptions of their self-esteem. Christian Education Journal, 12 (1), 45-57.

[20] Lai, L. C. H., \& Cummins, R. A. (2013). The contribution of job and partner satisfaction to the homeostatic defense of subjective wellbeing. Social Indicators Research, 111(1), 203-217.

[21] Lai, L. C. H., Cummins, R. A., \& Lau, A. L. D. (2013). Cross-cultural differences in subjective wellbeing: Cultural response bias as an explanation. Social Indicators Research, 114 (2), 607-619.

[22] LaMothe, R. (2005). An analysis of pride systems and the dynamics of faith. Pastoral Psychology, 53(3), 239-253.

[23] Luk, L. (2007). Spirituality, religion \& holistic health: Transcendency of human predicament. Hong Kong: Chung Sum Association Press.

[24] Pallant, J. (2020). SPSS survival manual: A step by step guide to data analysis using SPSS. London: Routledge.

[25] Parker, S. (1994). Let's be clear: Self-esteem is the problem, not the solution. Newsmagazine, 21 (19), 9-12.

[26] Peterson, C. (2000). The future of optimism. American Psychologist, 55, 44-56.

[27] Plante, T. G., Yancey, S., Sherman, A., \& Guertin, M. (2000). The association between strength of religious faith and psychological functioning. Pastoral Psychology, 48 (5), 405-412.

[28] Rosenberg, M. (1979). Conceiving the self. New York: Basic Books. 
[29] Rothbaum, F., Weisz, J. R., \& Snyder, S. S. (1982). Changing the world and changing the self: A two-process model of perceived control. Journal of Personality and Social Psychology, 42, 5-37.

[30] Russell, J. A. (2003). Core affect and the psychological construction of emotion. Psychological Review, 110 (1), $145-172$.

[31] Schweitzer, D. (2000). Pride as sin and virtue. Studies in Religion, 29 (2), 167-181.

[32] Steinfels, P. (1997). Murray Kempton, R. I. P. Commonweal., 124 (11), 13-25.

[33] Streams in the Desert (2020). Hong Kong: The Christians Press.
[34] Hogg, M., \& Vaughan, G. (2018). Social psychology. UK: Pearson.

[35] Warren, R. (2011). The purpose-driven life. USA: Zondervan.

[36] Waters, W. W. (1987). Christianity \&amp: Mental health. Humanist, 47(6), 5-32.

[37] Watts, F., Dutton, K., \& Gulliford, L. (2006). Human spiritual qualities: Integrating psychology and religion. Mental Health, Religion and Culture, 9 (3), 277-289.

[38] Weisz, J. R., Rothbaum, F. M., \& Blackburn, T. C. (1984). Standing out and standing in: The psychology of control in America and Japan. American Psychologist, 39 (9), 955-969. 